University of Nebraska - Lincoln

DigitalCommons@University of Nebraska - Lincoln

Faculty Publications, Department of Psychology

Psychology, Department of

March 1991

\title{
Personality and Socialization Correlates of Vicarious Emotional Responding
}

\author{
Nancy Eisenberg \\ Arizona State University, nancy.eisenberg@asu.edu \\ Richard Fabes \\ Arizona State University, rfabes@asu.edu \\ Mark Schaller \\ Arizona State University \\ Paul Miller \\ Arizona State University \\ Gustavo Carlo \\ University of Nebraska-Lincoln, carlog@missouri.edu \\ See next page for additional authors
}

Follow this and additional works at: https://digitalcommons.unl.edu/psychfacpub

Part of the Psychiatry and Psychology Commons

Eisenberg, Nancy; Fabes, Richard; Schaller, Mark; Miller, Paul ; Carlo, Gustavo; Poulin, Rick ; Shea, Cindy; and Shell, Rita , "Personality and Socialization Correlates of Vicarious Emotional Responding" (1991). Faculty Publications, Department of Psychology. 191.

https://digitalcommons.unl.edu/psychfacpub/191

This Article is brought to you for free and open access by the Psychology, Department of at DigitalCommons@University of Nebraska - Lincoln. It has been accepted for inclusion in Faculty Publications, Department of Psychology by an authorized administrator of DigitalCommons@University of Nebraska - Lincoln. 


\section{Authors}

Nancy Eisenberg, Richard Fabes, Mark Schaller, Paul Miller, Gustavo Carlo, Rick Poulin, Cindy Shea, and Rita Shell 


\title{
Personality and Socialization Correlates of Vicarious Emotional Responding
}

\author{
Nancy Eisenberg, Richard A. Fabes, Mark Schaller, Paul Miller, \\ Gustavo Carlo, Rick Poulin, Cindy Shea, and Rita Shell
}

Arizona State University

\begin{abstract}
The relations of personality and family characteristics to adults' negative vicarious emotional responses to sympathy and distress films were examined. Ss reported more sympathy and less personal distress and exhibited less skin conductance as well as heart rate deceleration when viewing a sympathy-evoking film. Dispositional emotional intensity and fantasy empathy were associated with greater self-reported emotional responding and higher skin conductance. Dispositional perspective taking and personal distress were positively and negatively correlated, respectively, with reported vicarious responding to the sympathy film when Ss were administered instructions to imagine the emotions of those in the films. Family cohesiveness was associated with reported sympathy and sadness in reaction to the sympathy film, whereas the expression of subordinate and positive emotional states in the home of origin was associated with women's reported responsivity.
\end{abstract}

The purpose of the present investigation was to examine the relations of personality characteristics and family socializationrelevant characteristics to adults' negative vicarious emotional responses. In contrast to most previous research on this topic, we examined these relations with physiological markers of emotional response in addition to the self-report indexes used in many social psychological studies.

In recent years, a number of researchers have attempted to differentiate among various types of vicarious emotional responding and to examine their motivational characteristics. Of primary interest has been the difference between sympathy (sometimes labeled empathy) and personal distress. Sympathy is an emotional reaction that is based on the apprehension of another's emotional state or condition, one that is not merely a reflection of the other's emotional state but involves feelings of concern and sorrow for the other person. In contrast, personal distress is an aversive reaction to another's state or condition, such as anxiety or discomfort, that results from another's emotional state or condition (Batson, Bolen, Cross, \& Neuringer-Benefiel, 1986). Both of these reactions may stem from empathy (a vicarious emotional response that is identical or very similar to that of the other person), although they also may occur as a consequence of cognitively taking the role of

This research was supported by National Science Foundation Grant BNS8807784 to Nancy Eisenberg and Richard A. Fabes and a Career Development Award from the National Institute of Child Health and Development K04 HD00717 to Nancy Eisenberg.

We thank Robert B. Cialdini for his comments on a draft and Neal Bechtel, Joseph Campos, and Ernest Lindholm for their advice regarding technical aspects of the study.

Mark Schaller is now at the Department of Psychology, University of Texas at Arlington. Paul Miller is now at the Department of Arts and Sciences, Arizona State University, West Campus.

Correspondence concerning this article should be addressed to Nancy Eisenberg, Department of Psychology, Arizona State University, Tempe, Arizona 85287. another or accessing information from one's memory (see Eisenberg, Shea, Carlo, \& Knight, in press).

The distinction between sympathy and personal distress is of particular interest because of their asserted motivational and behavioral correlates. Sympathy is viewed as involving an other orientation, which frequently results in the performance of altruistic behavior, whereas personal distress is associated with the motivation merely to alleviate one's own aversive emotional state. Although the research is not yet conclusive, there is considerable evidence supporting the differential relations of sympathy and personal distress to altruism, particularly among adults (e.g., Batson et al., 1986; Schroeder, Dovidio, Sibicky, Matthews, \& Allen, 1988).

Most of the recent research concerning vicarious emotional responses has been focused on the relation of sympathy and personal distress in a particular context (henceforth called situational sympathy and personal distress) to altruistic behavior (e.g., Batson, 1987; Batson et al., 1986; Eisenberg, Fabes, et al., 1989; Schroeder et al., 1988). In this research, investigators usually have not examined personality correlates of individual differences in vicarious responding, although they occasionally have explored the personality and demographic correlates of questionnaire measures of empathy (Davis, 1983; Mehrabian, 1980; see also Chlopan, McCain, Carbonell, \& Hagen, 1985). However, the degree of correspondence between dispositional and situational indexes of vicarious responding is unclear (Batson et al., 1986; Eisenberg, Miller, et al., 1989). Thus, information concerning the dispositional and socialization factors associated with sympathy and personal distress is needed and would aid in the understanding of other-oriented versus self-oriented motivation and behavior.

\section{Personality Influences}

There is reason to expect situational personal distress and sympathy to be differentially related to several types of personality variables. 
Dispositional Vicarious Emotional Responding and Perspective Taking

First, assuming that dispositions sometimes influence behavior in specific settings, one would expect dispositional and situational indexes of similar constructs to be associated, even if they are not comparable. For example, high levels of situational sympathetic responding would be expected to be associated with dispositional indexes of other-oriented concern. In addition, in circumstances that are not so arousing that empathizing is likely to lead to personal distress (see Eisenberg et al., in press; Hoffman, 1982), one might expect dispositional perspective taking to be associated with situational sympathetic responding. This is because the tendency to cognitively take the perspective of others has been hypothesized to be an important prerequisite or facilitator of sympathetic and empathic responding (Feshbach, 1987; Hoffman, 1982; Staub, 1978).

At this time, there is only limited empirical support for the aforementioned hypotheses. Self-reported situational sympathy has been associated with self-reported dispositional sympathy and perspective taking in several studies (Batson et al., 1986; Eisenberg, Fabes, et al., 1988; Eisenberg, Miller, et al., 1989) and with fantasy empathy (i.e., empathizing with characters from books, movies, and the like; Davis, 1983; Stotland, Mathews, Sherman, Hansson, \& Richardson, 1978) in some studies (Eisenberg, Miller, et al., 1989) but not in others (Batson et al., 1986). Although self-reported distress in a self-related distressing context has been associated with high scores on dispositional personal distress (Eisenberg, Schaller, et al., 1988), self- reported personal distress in sympathy-evoking settings has tended to be positively related to dispositional sympathy, perspective taking, or fantasy empathy rather than to dispositional personal distress (Batson et al., 1986; Eisenberg, Miller, et al., 1989). One reason for this discrepancy may be that people seem to interpret the words used to assess situational distress (e.g., distressed) as implying sympathetic concern in sympathy-evoking contexts (Batson et al., 1988). Another possibility is that dispositional indexes of sympathy and empathy but not state indexes are valid measures (Batson et al., 1986).

Unfortunately, self-report indexes of empathy and related reactions may be influenced by self-presentational and social desirability considerations (Archer, 1984; Cialdini et al., 1987; Eisenberg, Fabes, et al., 1989; Eisenberg \& Lennon, 1983), although there is debate in regard to the degree that this is so (Fultz, Batson, Fortenbach, McCarthy, \& Varney, 1986). Thus, it is important to examine the relation between dispositional and situational indexes of vicarious responding using non-self-report indexes. However, we are aware of only two studies in which nonself-report indexes of situational sympathy and personal distress were examined in relation to questionnaire indexes of empathy or related constructs. In one study involving second-grade children, there were modest associations between a global self-report questionnaire of empathy and heart rate (HR) deceleration and facial responding to films of others in emotionally evocative contexts (Eisenberg, Fabes, et al., 1988). In another study, adults' facial sadness during a sympathy induction was associated with scores on Davis's (1983) Empathic Concern (EC; i.e., sympathy) scale whereas facial distress during a distress induction was positively correlated with scores on the Personal Distress (PD) scale (Eisenberg, Schaller, et al., 1988). Additional research is needed in which non-self-report measures are used and in which social desirability is controlled, when examining the relations between self-reported dispositional indexes and self-reported situational emotional responding.

\section{Emotional Arousability}

Another personal variable that often is assumed to be related to sympathy and personal distress is emotional arousability (Mehrabian, 1980). By definition, empathy, sympathy, and personal distress all involve emotional arousal; therefore, people who are susceptible to high-intensity emotional reactions would be expected to exhibit more vicarious emotional responding in specific contexts. Indeed, the high positive correlations between measures of self-reported sympathy, personal distress, and sadness in the literature are probably due, in part, to the contribution of general emotionality to each.

The role of autonomic arousability (an aspect of temperament; Derryberry \& Rothbart, 1988) in situational vicarious emotional responding has seldom been examined. However, self-reported dispositional empathy on the Mehrabian and Epstein empathy questionnaire (which includes items possibly tapping empathy; sympathy; personal distress, fantasy empathy, and other constructs) has been positively related to a questionnaire index of arousal seeking and negatively related to stimulus screening (Mehrabian, 1980). It has been argued that certain types of people such as extraverts and emotionally arousable people may be physiologically underaroused and may seek out or create stronger emotional responses to increase their internal level of stimulation (Larsen, Diener, \& Cropanzano, 1987; Larsen, Diener, \& Emmons, 1986). In one study that is especially pertinent to an understanding of sympathy, people who scored higher on a questionnaire index of dispositional affective intensity used more statements reflecting empathy or perspective taking when describing their reactions to emotionally evocative slides (Larsen et al., 1987). However, it is possible that the aforementioned findings regarding an association between vicarious emotional responding and emotional arousability were due to the mere fact that some people are more willing to report emotional reactivity (on any self-report index, be it related to empathy or arousal) or are more aware of their emotional responding. Again, the need to examine the relation between situational vicarious emotional responding and dispositional indexes using non-self-report indexes is evident.

Because personal distress reactions are, by definition, aversive and distressing, it is quite possible that they typically are more arousing than are sympathetic reactions or empathic sadness. Indeed, it has been hypothesized that if people are overaroused as a result of empathizing, they are likely to experience their emotional reaction as personally distressing (Eisenberg et al., in press; Hoffman, 1982). Moreover, sadness appears to involve less arousal than does distress (Mehrabian, 1980), and caring, compassion, sympathy, and pity are seen as somewhat lower in intensity and activity than are distress, worry, anxiety, and tenseness (Shaver, Schwartz, Kirson, \& O'Connor, 1987). Thus, empathic sadness and sympathy might be expected to be less physiologically arousing than are feelings of personal distress, although both would be expected to be positively correlated with dispositional intensity of affective responding. 


\section{Socialization Correlates}

Another issue that has been infrequently examined is the socialization correlates of situational sympathy and personal distress. Researchers have hypothesized that sensitive, empathic parenting is associated with the development of an other orientation and empathic and sympathetic tendencies (Feshbach, 1987; Staub, 1986), and empirical support for the association between warm parenting and high scores on nondifferentiated self-report measures of empathy exists (Barnett, 1987). In one of the only studies in which investigators differentiated between children's sympathy and personal distress, maternal reports of dispositional sympathy and cognitive perspective taking were positively correlated with elementary school girls' (but not boys') self-reported situational sympathy, whereas maternal dispositional personal distress was negatively correlated to situational sympathy (Fabes, Eisenberg, \& Miller, 1990). In addition, maternal sympathy was associated with girls' HR deceleration (a marker of other orientation; see Eisenberg, Fabes, et al., 1988) when viewing needy others.

Unfortunately, most of the research concerning socialization correlates has involved self-report indexes of global vicarious responding (i.e., indexes in which sympathy and personal distress have not been differentiated) and has focused on the role of maternal variables (e.g., warmth and sympathy) in children's empathy. To our knowledge, there is virtually no research examining the role of family variables such as expressiveness in the family of origin and cohesiveness in offsprings' sympathy and personal distress. Because cohesive families would be expected to provide the kind of emotional support believed to facilitate empathy and sympathetic responding (Feshbach, 1987; Zahn-Waxler, Radke-Yarrow, \& King, 1979), it is reasonable to predict a positive association between cohesiveness of one's family of origin and the individual's sympathy. In addition, on the basis of Buck's (1984) theorizing, one would predict that sanctions for emotional expressiveness in the home would be associated with physiological but not self-report markers of vicarious responding. This is because children who receive negative reactions to displays of emotion would be expected to learn to hide their emotions but would also feel anxious when in emotionally evocative situations (because of prior associations between punishment and emotional expressivity).

In general, then, a positive relation between emotional expressivity in the home and self-reports of vicarious emotional responding in sympathy-evoking contexts could be predicted for several reasons: (a) Children in expressive families would be expected to learn that it is acceptable to express emotions, (b) positive emotionality in the family is likely to be indicative of parental warmth, which has been associated with empathy in children (see Barnett, 1987), and (c) socializers' willingness to discuss emotions with their children would be expected to relate to children's awareness of others' emotional states (Dunn, Bretherton, \& Munn, 1987). Indeed, in regard to (c), emotional schemata, which are undoubtedly influenced by the degree to which emotions are expressed and discussed in the home, are viewed as playing a crucial role in structuring emotional experience and in permitting the blending of experiences and the development of subtler feeling states such as are part of sympathy and empathy (Malatesta \& Haviland, 1985).
A few exceptions exist in regard to the hypothesized positive relation between emotional expressivity in the family and vicarious emotional responding. First, family expressiveness might actually be negatively related to vicarious responding if cues related to the other person's condition are very subtle. This is because people in expressive families may have less need to learn to decode subtle facial cues of emotion (Halberstadt, 1986). Second, negative, dominant emotional displays (Halberstadt, 1986) — such as anger, blaming, threatening, and putting down others - would not be expected to be associated with sympathy. Such expressiveness would not seem to facilitate an other orientation. In contrast, people who were raised in homes in which submissive negative emotions were frequently expressed - such as expressing sorrow when a pet dies, crying when someone leaves, or expressing disappointment when something didn't work out-would be expected to learn that it is acceptable to express other oriented sympathy and empathic sadness. In addition, because of learning related to the acceptability of negative expressivity, relatively high levels of negative expressivity in the home, submissive or dominant, might be expected to be correlated with reported distress in personally distressing contexts.

\section{Physiological Markers of Sympathy and Personal Distress}

The present study differed from most previous work in that we focused on the correlates of situational vicarious responding (rather than dispositional responding) and used non-self-report as well as self-report indexes of emotional response. The nonself-report indexes used in this study were HR and skin conductance (SC).

HR has proved to be a useful marker of sympathy and personal distress. HR deceleration has been observed in contexts in which empathic sadness and a sympathetic response are likely (Campos, Butterfield, \& Klinnert, 1985; Craig, 1968; Eisenberg, Fabes, et al., 1988; Eisenberg, Schaller, et al., 1988) and has been positively associated with helping behavior among school-age children and adults (Eisenberg, Fabes, et al., 1989). In contrast, HR acceleration has been noted in contexts in which people are fearful or anxious (e.g., Craig, 1968; Eisenberg, Fabes, et al., 1988) or are discussing personally distressing memories (Eisenberg, Schaller, et al., 1988). Because sympathy implies an outward other orientation, the aforementioned findings are consistent with literature indicating that an outward focus of attention (i.e., when taking in information from the environment) is associated with HR deceleration (Cacioppo \& Sandman, 1978; Lacey, Kagan, Lacey, \& Moss, 1963). In addition, active coping and anxiety about one's welfare have been associated with HR acceleration in a number of studies (e.g., Cacioppo \& Sandman, 1978; Lacey et al., 1963; Lazarus, 1974); thus, it is logical to expect HR acceleration to accompany a self-focused personal distress reaction.

$\mathrm{SC}$ has been viewed as an indirect index of defensive arousal, cortical activation, or alertness for information input (Edelberg, 1972) and has been associated with intensity of response (e.g., Jackson, 1974; Lanzetta, Cartwright-Smith, \& Kleck, 1976) and with vicariously induced emotional reactions (e.g., Craig \& Lowery, 1969; Krebs, 1975). It is frequently used as an index of arousal (Zillman, 1982), although it may reflect other processes. Findings regarding SC as a marker of specific emotions have been 
quite inconsistent (Schwartz, 1986). Thus, it is not clear whether higher levels of SC should be interpreted as an index of intensity of emotional response, be it sympathetic or distressed, or primarily as an index of personal distress. However, given that higher arousal is associated with distressed than with sympathetic reactions (Shaver et al., 1987), more SC was expected in reaction to a distressing stimulus film than in reaction to a film expected to evoke sympathy but relatively little distress.

An interesting issue concerns which dispositional indexes relate to self-report indexes of situational vicarious emotional reactions and which relate to nonverbal indexes (i.e., HR and SC). Physiological reactions and more overtly expressive modes of emotional response (facial reactions, verbal responses) tend not to be positively interrelated (Buck, 1984; Notarius \& Levenson, 1979); thus, different dispositional characteristics may relate to different modes of emotional responsiveness. One might expect that people who view themselves in a certain manner (e.g., as sympathetic) and are willing to say so on questionnaires tapping dispositional characteristics would be especially likely to report experiencing reactions consistent with their self-perceptions (or self-presentation). Thus, it is reasonable to expect dispositional indexes of vicarious responding, perspective taking, and other orientation to be correlated with self-report indexes of situational response. In contrast, SC responding may be unrelated to most self-report indexes of dispositions or may be particularly associated with those concerning arousability. If HR is used as an index of attention in a given context rather than arousal, it would not be expected to relate to dispositional indexes, which generally has been the case (Eisenberg, Fabes, et al., 1988; Eisenberg, Schaller, et al., 1988). If various dispositional indexes correlate differently with different indexes of vicarious responding, the results could be interpreted as supporting the importance of using multiple approaches to assessing empathy and sympathy.

\section{Method}

\section{Subjects}

Participants were 44 male and 50 female (mean age $=19$ years) undergraduate students. Most were White and participated for partial course credit in their introductory psychology course. Eight additional subjects were dropped because of errors in procedures or major equipment failures, and a number of other subjects had only partial data because of problems with the SC equipment (full data were available for 80 people for the sympathy film and 81 for the distress film) and HR equipment (full data were available for 89 people for the sympathy film and 91 for the distress film).

\section{Overview}

Subjects participated in two sessions: one in which most of the socialization and dispositional indexes were administered and one in which situational sympathy and personal distress were assessed by means of self-reports, HR, and SC.

\section{Personality and Socialization Measures}

The questionnaire measures used in the study were as follows: (a) the Marlowe-Crowne Social Desirability Scale (Crowne \& Marlowe, 1964; $\alpha$ =.73); (b) Davis's (1983) Interpersonal Reactivity Index (IRI), with four subscales (EC, sympathetic concern; PT, perspective taking; FE, fantasy empathy; and PO, personal distress; $\alpha$ s $=.73, .78, .81$, and .73 , respectively); (c) Larsen's (Larsen et al., 1987) Affect Intensity Measure (AIM; $\alpha=.87$ ), which assesses typical intensity of emotional responding; (d) the Family Cohesiveness subscale of Moos and Moos's (1981) Family Environment Scale $(\alpha=.85)$; and (e) Halberstadt's (1986) Family Expressiveness Questionnaire.

The Family Expressiveness Questionnaire has subscales assessing the degree to which family members express dominant positive and negative emotions ( $\alpha \mathrm{s}=.85$ and .82 , respectively) and submissive positive and negative emotions ( $\alpha \mathrm{s}=.86$ and .65 , respectively). Positive dominant emotions include such things as showing forgiveness to a family member who broke a possession, spontaneously hugging a family member, or expressing concern for the success of other family members. Submissive positive emotions include seeking approval, expressing sympathy for someone's troubles, and offering to do somebody a favor. Negative dominant emotional expressiveness includes threatening or criticizing someone, blaming one another for family troubles, and expressing dissatisfaction with someone else's behavior. Examples of negative submissive emotional displays are expressing sorrow when a pet dies, crying when someone leaves, or apologizing for being late. Subjects were instructed to fill out the Family Cohesiveness and Family Expressiveness Scale subscales in reference to their families of origin.

\section{Stimulus Films}

Two stimulus films were used to evoke emotional responses akin to sympathy and personal distress. One film was selected to evoke empathy and sympathy; it is a film about a child with spina bifida. The child talks in a neutral to positive tone in most of the film but is shown having difficulty walking during a therapy session. This film has been found to elicit sympathy in prior research (e.g., Eisenberg, Fabes et al., 1988; Strayer $\&$ Schroeder, 1989). The segment of the film used in this study was 208 $\mathrm{s}$ long and contained about $20 \mathrm{~s}$ of relatively neutral content before it became clear that the child has spina bifida, $62 \mathrm{~s}$ of relatively evocative content (that was based on a priori consensus of psychologists), and a particularly evocative short section near the end when the child attempts to walk ( $7 \mathrm{~s}$ total, 5 particularly evocative s). The second film was selected to elicit personal distress; it was about a young man who picks up a hitchhiker. It became apparent that the hitchhiker was not normal, and at the end of the film, he said that he had cut up a person with whom he had hitched a ride and that he was going to do the same to the young man who picked him up. The film clip was $190 \mathrm{~s}$ long, containing $15 \mathrm{~s}$ of neutral time and $62 \mathrm{~s}$ of relatively distressing content, including the very evocative section at the end which was $16 \mathrm{~s}$ long (with $5 \mathrm{~s}$ of especially evocative time). The sympathy and distress films were preceded by 38 and $33 \mathrm{~s}$ of colored bars, respectively.

\section{Procedures}

The experiment required a questionnaire session and an experimental session.

Questionnaire session. Participants appearing at the initial session were informed that the materials for the study were not yet prepared and that another experimenter was conducting a different study and needed subjects to complete some questionnaires. Subjects were told that they would be involved in a shortened version of the original study in a second session to complete their participation time. All subjects agreed to fill out the questionnaires, and they were then scheduled for the second experimental session approximately a week later. At this first session, participants were administered all of the questionnaires except the Family Expressiveness Scale.

Experimental session. The second part of the study took place in a different part of the building and was conducted by different experiment- 
ers. The sessions were arranged in this way to reduce the likelihood that participants would perceive a relation between the two sessions.

On arrival, participants were told that they would be viewing two tapes and that we were interested in their reactions to, and evaluations of, the tapes. Then an experimenter attached 8-mm silver-silver chloride electrodes to the palmar surface of subjects' nondominant hand. While the subject waited for about $15 \mathrm{~min}$ (so that the electrolyte jelly in the electrodes penetrated the skin), he or she filled out the Family Expressiveness Scale.

Next, a same-sex experimenter took the participant into the experimental room and placed HR electrodes on the left side of the subject, one on the chest just below the clavicle near the sternum and one above the clavicle on the shoulder. Subjects then viewed one of the two films (order was counterbalanced across subjects). Before viewing the first film, observational set was manipulated. Approximately half of the subjects were assigned to a sympathy set condition (henceforth called the imagine condition), whereas the remaining subjects were assigned to the observe condition, in which they were asked to objectively observe the events in the tapes. Subjects read the set instructions to themselves; the experimenter was unaware of which set of instructions subjects received. The set instructions were very similar to those used by Davis, Hull, Young, and Warren (1987). In the imagine condition, people were instructed to try to imagine how the story protagonist felt, to identify with his or her feelings, to visualize how it felt, and to concern oneself with the protagonist's feelings rather than with individual behaviors. In the objective set, subjects were instructed to make careful observations of the characteristics of the story protagonist's behaviors, including the frequency and patterning of behavior.

During the film, the subject's SC and HR were monitored. While the subject viewed the films, his or her arm with the SC electrodes attached was strapped loosely to the arm of the chair to prevent movement. Subjects were videotaped unbeknownst to them through a one-way mirror while they viewed the tapes. After viewing the first film, subjects were asked to complete a mood adjective list with the instruction to indicate "how much you were feeling each of the following emotions while watching the preceding film clip" (order of the adjectives was counterbalanced across subjects). The mood questionnaire contained a list of 15 emotion-related adjectives; subjects rated the degree to which they were feeling each on a 7-point scale ranging from not at all (1) to extremely (7). Included were adjectives reflecting sympathetic feelings (sympathetic, touched, compassionate, concerned about others, softhearted), PD (disturbed, troubled, uneasy, alarmed, distressed about self), and sadness (low-spirited, sad, feeling low, sorrowful, heavyhearted), most of which have been used in prior research (e.g., Batson et al., 1986; Eisenberg, Schaller, et al., 1988). Then subjects were asked several questions about the film -including how interesting it was, to what extent they carefully observed the behaviors of the character they were assigned to watch, and to what extent they concentrated on imagining the feelings of the character.

After completing the adjective list, subjects filled out several questionnaires unrelated to this study. This was done, in part, to allow any emotional reaction to the first film to dissipate.

Next, the experimenter readministered the instructional set instructions, and subjects viewed the remaining film. Then they filled out the mood adjective rating form once more, after which a balloon was suddenly popped near the subject. This was done to determine whether the $\mathrm{SC}$ electrodes were still functional; if so, one would expect arise in SC (this test was used to eliminate subjects who had shown no response throughout the session). Finally, subjects were debriefed and were asked if they were willing to sign a release to allow us to use the videotapes of them for research purposes. (All agreed.)

\section{Data Coding}

$H R$. HR data were recorded onto audiotapes for entry into the computer. The HR samplings (collected every $10 \mathrm{~ms}$ ) were used to ' 1 compute mean HR per 1/2-S period (see Graham, 1978). When there was artifact in the HR data that was due to movement (which occurred relatively infrequently), the average of the last codable beat and the first codable beat after the artifact was used in place of the uncodable data points (however, usually the 10-ms samplings could be used to determine when the heart beat occurred).

Critical segments of the films had been chosen by several psychologists before the study. For the sympathy film, the critical point was the section near the end when the child with spina bifida was attempting to walk and was having difficulty. For the distressing film, the critical segment was the segment at the end when the hitchhiker said he was going to cut apart the driver. For both segments, a 5 -s period (containing ten $1 / 2$ $\mathrm{S}$ periods) was used (the segments had to be equal lengths for the trend analyses). The entire tape could not be used because not all sections were evocative and because HR responses are relatively quick (and tend to return to baseline).

$S C$. SC data were also stored on audiotape and then run through a program that picked up and measured phasic responses. SC data for subjects with no SC responses, even in response to the popped balloon, were dropped from analyses (because the electrodes probably were not transmitting correctly). Phasic responses were those of $0.05 \mu$ mho or larger (although responses of 2.5 or larger were assumed to be artifact). For 5 subjects, the audiotapes were unreadable, so data were obtained by hand from polygraph outputs. Because phasic responses are relatively slow and we wanted to assess number of responses and mean amplitude of responses, we assessed SC during a slightly longer portion of the critical periods (16 s for the distress film and 7 for the sympathy film; i.e., all of the critical segments, not equal portions of the most evocative part, were used). In addition, we computed SC during the $62 \mathrm{~s}$ of relatively evocative content in each film to use in some exploratory analyses (this segment reflected SC to all the relatively evocative parts of the film, not simply the most evocative segment). The critical period for the distress film was longer than that for the sympathy film (and some analyses involved across-film comparisons); therefore the number of SC responses was converted to rate per minute. To control for individual differences in $\mathrm{SC}, \mathrm{SC}$ was standardized within each individual.

Because relatively small movements can affect SC, coders coded subjects' movements from the videotapes on a 4-point scale, ranging from no movement (1) to slight head movement of less than $45^{\circ}(2)$ to larger head movement (3) to significant movement of trunk of body (4). Any phasic response occurring within $5 \mathrm{~s}$ after a movement that had been coded a 3 or 4 was removed from the data (exact agreement on whether a movement was a 3 or 4 , computed for half the data, was $80 \%$ ). Movements were relatively infrequent, and some editing was performed for only about $15 \%$ of subjects. ${ }^{2}$

Self-reported reactions. We computed composite indexes of emotional response by determining the mean ratings for the adjectives in each composite index. Alphas for the various composites ranged from .81 to .91 .

${ }^{1}$ Because some subjects exhibited no phasic responses or only one response during a film (even if they responded to the balloon pop), standardizing could not be done using within-subject standard deviations (Ben-Shakhar, 1987; Stemmler, 1987). Thus, number of responses and mean response during the critical periods were standardized within each film and each person by dividing by the number (or amplitude) of a person's response by the total number of responses (or mean amplitude of responses) for the entire film

2 The videotapes were used to assess facial expressions as well as movement. However, our adults subjects exhibited relatively little emotional response (as in Eisenberg, Fabes, et al., 1989), and only gaze aversions (i.e., turning of the eyes from the television screen) differed across films (with more for the distress film). Thus, these videotape data are not discussed. 


\section{Results \\ Manipulation Check for Set Induction}

To determine whether subjects understood the observational set instructions (and reported following them), we computed a 2 (sex) $\times 2$ (order) $\times 2$ (set) multivariate analysis of variance (MANOVA) for each film with the dependent variables being (a) report of how much subjects concentrated on imagining the feelings of the character they were assigned to watch and (b) the extent to which they carefully observed the behaviors of the characters they were assigned to watch. For both films, the multivariate $F$ s were significant for set, $F(2,84)=14.51$ and $F(2,83)=11.85$, $p \mathrm{~s}<.001$, for sympathy and distress films, respectively. The univariate $F$ s were significant for the extent of imagining in the empathy and distress films, $F(1,85)=49.56$ and $F(1,84)=48.20$, ps $<.001$, respectively; the univariate $F$ s for observing were not significant. Thus, subjects who were instructed to imagine the protagonists' plight reported doing so, but those instructed to imagine and to observe objectively did not differ in reported degree of attending to the behaviors of the characters. ${ }^{3}$ Moreover, according to an additional analysis, observational set did not affect subjects' liking of the film protagonists.

\section{Differences in Response Across Films}

To determine whether our film clips differed in the degree to which they elicited vicariously induced sympathy and distress, we compared self-reported responses, HR responses, and SC responses to the two films.

Self-reports. Differences in self-reported reactions across films were examined with a $2($ sex $) \times 2$ (order) $\times 2$ (set) $\times 2$ (film) repeated measures MANOVA. The dependent variables were reported sadness, sympathy, and personal distress after each of the films.

Subjects generally reported emotional reactions in keeping with the content of the films. The multivariate $F$ s were significant for the main effects of order, sex, and film, $F \mathrm{~s}(3,84)=$ $3.02,5.98$, and 64.05, $p \mathrm{~s}<.034, .001$, and .001, respectively, as well as for the interactions of Sex $\times$ Film and Order $\times$ Film, $F(3,84)=2.70$ and $3.73, p$ s $<.051$ and .014 , respectively. According to univariate analyses, more sadness $(M=3.10)$ and sympathy $(M=4.52)$ were reported when the distress film was presented first rather than second $(M \mathrm{~s}=2.51$ and 3.88 , respectively), $p \mathrm{~s}<.009$; women reported more sympathy $(M=4.53)$ than did men $(M=3.80), p<.001$; and more personal distress was reported for the distress $(M=4.42)$ than sympathy film $(M$ $=2.56)$, whereas the reverse was true for sympathy $(M \mathrm{~s}=4.84$ and 3.53$), p s<.001$. Subjects also tended to report more sadness in response to the sympathy film $(M=2.90)$, rather the distress film $(M=2.69), p<.059$. In addition, there was a significant univariate Order $\times$ Film effect for reported personal distress, $p<.011$, which was due to the fact that difference across films in reported distress was merely larger when the sympathy film was viewed first, $F(1,45)=101.45, p<.001$, rather than second, $F(1,41)=21.81, p<.001$. Similarly, although both sexes reported more distress in response to the distressing film, the difference across films was larger for women than for men,
$F(1,46)=70.32$ and $F(1,40)=33.95, p s<.001$, respectively $(p<.006$ for the Sex $\times$ Film univariate for reported personal distress; see Table 1 for means by sex and film).

$S C$. We computed similar $2($ sex $) \times 2$ (order) $\times 2$ (set) $\times 2$ (film) repeated measures MANOVAs to examine differences in $\mathrm{SC}$ across the two films. As expected, SC was greater in the distress film than in the sympathy film. For the two standardized SC scores (number of phasic responses and mean amplitude of phasic responses) during the critical segments of the two films, the multivariate $F$ for the main effect of film was significant, $F(2,66)=$ $10.73, p<.001$. Both number (rate per minute, standardized) and amplitude of phasic SC (standardized) were higher in the distress film $(M \mathrm{~s}=0.083$ and 0.56 , respectively) than in the sympathy film $\left(M \mathrm{~s}=0.025\right.$ and 0.26 , respectively), $F_{\mathrm{s}}(1,67)=20.20$ and $11.29, p \mathrm{~s}<.001 .^{4}$ In addition, the multivariate $F$ for sex was significant, $F(2,66)=3.17, p<.049$; the number of phasic responses during the critical periods of the films was higher for women than for men, $F(1,67)=6.30, p<.015 .{ }^{5}$ Given the fact that the standardized scores for mean amplitude and number of phasic responses were significantly correlated, $r \mathrm{~s}(66)=.41$ and .55 , $p \mathrm{~s}<.001$, for the sympathy and distress films, respectively; and the mean number index differed somewhat more across films (see previous analyses and footnote 4), only scores for mean number were used in subsequent analyses.

$H R$. We examined differences in the HR trends during the critical segments of the two films with a $2($ sex $) \times 2$ (order) $\times 2$ (set) $\times$ 2 (film) $\times 13$ (one-half-s HR periods) repeated measures multivariate trend analysis. Both film and the HR periods were treated as within-subjects variables. The $13 \mathrm{HR}$ periods included three $1 / 2$-s periods before the critical period followed by 10 more periods. The Film $\times$ Linear Trend interaction was significant, $F(1,79)=9.07, p<.005$. According to tests of simple effects, HR decelerated during the sympathy film, $F(1,79)=8.88, p<.01$; the trend for the distress film was not significant. The latter finding may be due to subjects being aroused before the critical segment (the portion of the film preceding the critical segment of the distress film was moderately scary), which prevented further HR acceleration. This explanation for the lack of HR acceleration during the distress film is supported by the finding that mean HR during the critical segment was marginally higher in the distress film $(M=72.29)$ than in the sympathy film $(M=70.89)$, $F(1,77)=3.72, p<.058$.

\footnotetext{
${ }^{3}$ Our limited success with this manipulation is consistent with some other researchers' findings (e.g., Coke, 1980; Fultz, 1984) and is not surprising considering the low association between empathy as created with such a set manipulation and prosocial behavior (which conceptually would be expected to be associated with empathy) in the literature (Eisenberg \& Miller, 1987).

${ }^{4}$ The pattern of findings was similar for unstandardized scores during the critical periods of the films. In addition, for the $62 \mathrm{~s}$ of evocative content during the two films, mean number and amplitude of SC both were higher in the distress film for unstandardized scores, $p \mathrm{~s}<.001$, whereas only mean number of phasic responses was higher in the distress film for standardized scores, $p<.001$.

${ }^{5}$ However, it is interesting to note that women who scored higher on empathic concern exhibited higher SC across all the evocative portions of the sympathy film (i.e., the 62-s segment), partial $r(35)=.38, p<.02$.
} 
Table 1

Means and Standard Deviations of Indexes of Situational Emotional Responding

\begin{tabular}{|c|c|c|c|c|c|c|c|c|}
\hline \multirow[b]{3}{*}{ Index } & \multicolumn{4}{|c|}{ Sympathy film } & \multicolumn{4}{|c|}{ Distress film } \\
\hline & \multicolumn{2}{|c|}{ Women } & \multicolumn{2}{|c|}{ Men } & \multicolumn{2}{|c|}{ Women } & \multicolumn{2}{|c|}{ Men } \\
\hline & $M$ & $S D$ & $M$ & $S D$ & $M$ & $S D$ & $M$ & $S D$ \\
\hline \multicolumn{9}{|l|}{ Self-report } \\
\hline Sympathy & 5.20 & 1.24 & 4.44 & 1.27 & 3.86 & 0.30 & 3.16 & 0.15 \\
\hline Personal distress & 2.51 & 1.27 & 2.61 & 0.53 & 4.82 & 2.72 & 3.96 & 1.55 \\
\hline Sadness & 2.93 & 1.24 & 2.86 & 1.00 & 2.78 & 1.32 & 2.60 & 1.14 \\
\hline Heart rate & 72.69 & 9.43 & 68.95 & 13.93 & 74.32 & 9.09 & 69.37 & 14.16 \\
\hline Skin conductance & 0.04 & 0.09 & 0.01 & 0.02 & 0.10 & 0.12 & 0.06 & 0.09 \\
\hline
\end{tabular}

${ }^{a}$ Rate per minute standardized within individuals.

Interrelations among indexes of vicarious emotional response. To examine the relation between HR response during the critical period (i.e., the trend) and $\mathrm{SC}$ and self-report indexes, participants were classified according to whether they exhibited HR acceleration or deceleration during the critical segment of each of the two films. HR acceleration versus deceleration was unrelated to SC in either film. HR deceleration in the sympathy film was associated with self-reported sympathy, point-biserial $r(86)=-.22, p=.039$; HR was unrelated to self-reported reactions to the distress film. SC during the distress film was positively related to self-reported distress in reaction to that film, $r(79)=.24, p<.03$.

\section{Relations of Personality Variables to Vicarious Emotional Responding}

We examined the relations between the personality measures and the indexes of vicarious emotional responding with correlational analyses. Zero-order correlations, as well as correlations in which order, social desirability; and sex were partialed, were computed. Order of the films was partialed because order was related to self-reported reactions (see previous section), as well as to HR deceleration versus acceleration during the distress film, $p$ $<.036$ (HR acceleration was more likely when the distress film was presented second). Scores on the Marlowe-Crowne Social Desirability Scale were controlled (which resulted in the loss of 1 subject with missing data on the Social Desirability Scale) because they not only were negatively associated with report of sadness and distress after viewing the distressing film, $r \mathrm{~s}(91)=-.21$ and $-.21, p_{\mathbf{s}}<.042$ and .051 , respectively; but also were positively correlated with a number of other personality indexes (see Table 2). With regard to sex, women exhibited more SC in the critical segments of both the distress and sympathy films $(p \mathrm{~s}<.044$ and .033 , respectively) and reported more sympathy in reaction to the distress and sympathy films $(p s<.013$ and .004 , respectively) and more distress in response to the distressing film ( $p<$ $.011)$. In addition, women scored higher than men on a variety of the personality indexes, including the AIM $(p<.002)$, Family Expressiveness Questionnaire $(p<.002)$, EC $(p<.001)$, PD $(p<.019)$, PT $(p<.005)$, and FE $(p<.002)$. Therefore, sex also was controlled in the partial correlations. Observational set had little influence on the indexes of vicarious responding (see previ- ous analyses) and therefore was not considered in most analyses related to correlates of vicarious responding.

The relation of affective intensity to vicarious emotional reactions. The correlations between affective intensity and vicarious emotional arousal are presented in Table 3. AIM scores were positively correlated with affective reactions to the distressing film, particularly distressed reactions. In addition, people high in affective intensity exhibited relatively high levels of SC while viewing the evocative portion of the sympathy film. Thus, dispositional affective intensity was associated with more intense reactions to the films (both self-reported and physiological responses).

Relations of indexes of dispositional vicarious responding, expressivity, and perspective taking to situational vicarious emotional reactions. For the total sample combined across observational conditions, there were few relations of indexes of sympathy, perspective taking, personal distress, or expressivity to vicarious responding. As might be expected, personal distress was positively related to reported distress during the sympathy film, partial $r(88)=.17$, but this relation was only marginally significant $(p<.10)$. However, fantasy empathy, which assesses the dispositional tendency to react emotionally to movies, books, and other stimuli involving imaginal processes, was positively related to vicarious responding to both films as assessed by SC, partial $r(75)$ $=.27, p<.018$, and partial $r(76)=.34, p<.002$, respectively (zero-order correlations were .28 and .32 , respectively).

On the basis of prior research (e.g., Batson et al., 1986; Eisenberg, Schaller, et al., 1988), it was somewhat surprising that empathic concern, perspective taking, and personal distress, were not more often associated with subjects' self-reported emotional reactions. Thus, we examined the relations between reported reactions to the films and empathic concern, perspective taking, and personal distress within the two observational sets because instructions to observe objectively may have affected the emotional responding and perspective taking activities of persons high in dispositional empathic concern, personal distress, and perspective taking. For the sample in the observe condition (controlling for social desirability, sex, and order), the only finding was a marginal negative correlation .between perspective taking and reported sadness during the sympathy film, partial $r(41)=-.29, p<.058,(r=-.24, n s$, for distress $)$. However, in the imagine set, the pattern of relations for perspective 
Table 2

Intercorrelations of Personality and Family Variables

\begin{tabular}{|c|c|c|c|c|c|c|c|c|c|}
\hline \multirow[b]{2}{*}{ Variable } & \multicolumn{5}{|c|}{ Personality variable } & \multicolumn{4}{|c|}{ Family variable } \\
\hline & 2 & 3 & 4 & 5 & 6 & 7 & 8 & 9 & 10 \\
\hline \multicolumn{10}{|l|}{ Personality } \\
\hline 1. SD & .12 & $.36^{* * *}$ & -.11 & $.37^{* * *}$ & -.10 & $.27 * *$ & $-.35^{* * *}$ & -.03 & $.31^{* *}$ \\
\hline 2. AIM & - & $.42^{* * *}$ & $.37 * * *$ & -.01 & $.37 * * *$ & $.22 *$ & $.23^{*}$ & $.34 * * *$ & -.04 \\
\hline 3. EC & $.35^{* * *}$ & - & .15 & $.44^{* * *}$ & $.34^{* * *}$ & -.08 & -.01 & -.04 & -.13 \\
\hline 4. $\mathrm{PD}$ & $.33^{* * *}$ & .14 & - & .00 & .13 & .14 & .10 & .20 & -.01 \\
\hline 5. PT & -.15 & $.29 * *$ & -.03 & - & .11 & -.03 & -.09 & .00 & .15 \\
\hline 6. FE & $.31^{* *}$ & $.33^{* * *}$ & -.03 & .08 & - & -.02 & $.29^{* *}$ & $.31^{* *}$ & .10 \\
\hline \multicolumn{10}{|l|}{ Family } \\
\hline 7. $\mathrm{PE}$ & .21 & -.21 & .18 & -.15 & .05 & - & $-.25^{*}$ & $.39^{* * *}$ & $.62^{* * *}$ \\
\hline 8. Dominant $\mathrm{NE}$ & $.25^{*}$ & .08 & .01 & -.01 & $.23^{*}$ & $-.24^{*}$ & - & $.42^{* * *}$ & $-.45^{* * *}$ \\
\hline 9. Sub NE & $.28^{* *}$ & -.13 & .13 & -.07 & $.23^{*}$ & $.41^{* * *}$ & $.41^{* * *}$ & - & .04 \\
\hline 10. Cohesion & -.03 & $-.23^{*}$ & .08 & $-.26^{*}$ & -.01 & $.62^{* * *}$ & $-.44^{* * *}$ & .11 & - \\
\hline
\end{tabular}

Note. $\mathrm{SD}=$ social desirability; $\mathrm{AIM}=\mathrm{Affect}$ Intensity Measure $\mathrm{EC}=$ empathic concern (i.e., sympathy) $\mathrm{PD}=$ personal distress; $\mathrm{PT}=$ perspective taking; $\mathrm{FE}=$ fantasy empathy; $\mathrm{PE}=$ positive expressivity; $\mathrm{NE}=$ negative expressivity; $\mathrm{Sub}=$ submissive. The two PE scales were highly intercorrelated and averaged. Zero-order correlations are above the diagonal, whereas correlations partialing sex and SD are below the diagonal.

${ }^{*} p<.05 .^{* *} p<.01 .{ }^{* * *} p<.001$.

taking was reversed; perspective taking was positively correlated with reported sadness, sympathy, and distress in reaction to the sympathy-evoking film (see Table 4). In addition, personal distress was negatively related to reported sympathy in reaction to the sympathy film and, marginally, positively related to reported distress. There were no significant relations between empathic concern, perspective taking, or personal distress and reported reactions to the distressing film for the total sample once the effects of sex, order, and social desirability were partialed; however, zero-order correlations suggested a positive relation between personal distress and vicarious responding to the distressing film.

\section{The Association of Family Variables to Vicarious Emotional Responding}

Cohesiveness. Scores on the Family Cohesiveness scale were correlated with social desirability (see Table 2); thus, social desirability; as well as sex and order, were controlled in the analyses pertaining to this scale. Although family cohesiveness was unre-

Table 3

Correlations of Dispositional Affective Intensity With Vicarious Emotional Responding (Zero-Order and Partial Correlations)

\begin{tabular}{llllll}
\hline & \multicolumn{5}{c}{ Self-report } \\
\cline { 2 - 4 } Correlation & Sympathy & Sad & Distress & SC & HR \\
\hline Sympathy film & & & & & \\
$\quad$ Zero-order & $.17^{*}$ & .06 & .02 & $.26^{* *}$ & -.05 \\
$\quad$ Partial & .07 & .02 & -.02 & $.23^{* *}$ & -.02 \\
Distress film & & & & & \\
$\quad$ Zero-order & $.26^{* *}$ & $.22^{* *}$ & $.28^{* * *}$ & .07 & .00 \\
$\quad$ Partial & .16 & $.20^{*}$ & $.30^{* * *}$ & .05 & .01 \\
\hline
\end{tabular}

Note. Partial correlations partialed sex, order, and social desirability. $\mathrm{SC}=$ skin conductance; $\mathrm{HR}=$ heart rate.

${ }^{*} p<.10 .{ }^{* *} p<.05$. ${ }^{* * *} p<.01$. lated to SC or to HR acceleration or deceleration indexes, it was significantly related to self-reported sympathy and sadness in reaction to the sympathy-inducing film, partial $r \mathrm{~s}(88)=.23$ and .21 , $p$ s $<.028$ and .044 , respectively.

Family expressivity. The relations of reported emotional expressivity in the home to indexes of vicarious responding also were examined with partial correlations. The Positive Dominant and Positive Submissive subscales were intercorrelated, $r(88)=$ $.87, p<.001$, and the pattern of relations was the same for both; thus, scores for the two scales were averaged. The two negative scales were significantly interrelated, $r(88)=.42, p<.001$; however, the patterns of relations for these two subscales were quite different. Thus, they were not combined. Because of the correlation between social desirability scores and scores for positive expressivity and dominant negative expressivity (see Table 2), social desirability (as well as order) was partialed from correlations pertaining to the indexes of family expressivity. In addition, because of the aforementioned gender differences in reported vicarious reactions, the fact that women scored higher than men on negative submissive expressivity in the family $(p<.005)$, andmost important - the striking difference in patterns of correlations for men and women, correlations are presented for each sex as well as for the total sample.

We found numerous relations between emotional expressivity in the home and self-reported reactions. Although numerous correlations were significant for the total sample, they were due primarily to the strength of the correlations for women. Indeed, none of the correlations were even marginally significant for men's self-reports of vicarious emotion. As can be seen in Table 5 , report of the expression of positive emotion in the home was at least marginally significantly positively related to the report of sadness and sympathy in reaction to both films and the report of distress in reaction to the sympathy film. The Negative Dominant scale was not significantly related to report of emotional reactions to the films. In contrast, scores for negative submissive emotion were significantly positively related to self-reported sadness and sympathy reactions to both films and to distress in reaction to the distressing film. 
Table 4

Correlations Between Components of the Davis Dispositional Empathy Measures and Situation Vicarious

Emotional Reactions: Imagine Observation Set

Self-reported reaction

\begin{tabular}{|c|c|c|c|c|c|c|c|c|c|c|c|c|}
\hline \multirow[b]{3}{*}{ Trait } & \multicolumn{6}{|c|}{ Sympathy film } & \multicolumn{6}{|c|}{ Distress film } \\
\hline & \multicolumn{2}{|c|}{ Sympathy } & \multicolumn{2}{|c|}{ Sad } & \multicolumn{2}{|c|}{ Distress } & \multicolumn{2}{|c|}{ Sympathy } & \multicolumn{2}{|c|}{ Sad } & \multicolumn{2}{|c|}{ Distress } \\
\hline & $\begin{array}{l}\text { Zero- } \\
\text { order }\end{array}$ & Partial & $\begin{array}{l}\text { Zero- } \\
\text { order }\end{array}$ & Partial & $\begin{array}{l}\text { Zero- } \\
\text { order }\end{array}$ & Partial & $\begin{array}{l}\text { Zero- } \\
\text { order }\end{array}$ & Partial & $\begin{array}{l}\text { Zero- } \\
\text { order }\end{array}$ & Partial & $\begin{array}{l}\text { Zero- } \\
\text { order }\end{array}$ & Partial \\
\hline PT & $.32^{* *}$ & $.25 *$ & $.41^{* * *}$ & $.47^{* * * *}$ & $.42^{* * *}$ & $.47^{* * * * *}$ & .17 & .12 & .18 & .25 & -.02 & .05 \\
\hline $\mathrm{EC}$ & $.24^{*}$ & .07 & .11 & .07 & .08 & .02 & .21 & .07 & .02 & .01 & .09 & .15 \\
\hline PD & -.10 & $-.33^{* *}$ & $.25^{*}$ & .15 & $.30^{* *}$ & $.25^{*}$ & $.28^{*}$ & .06 & $.30^{* *}$ & .18 & .15 & -.06 \\
\hline $\mathrm{FE}$ & .20 & .04 & $.26^{*}$ & .15 & .13 & -.01 & .22 & -.01 & .15 & .02 & $.29^{* *}$ & .22 \\
\hline
\end{tabular}

Note. $\mathrm{PT}=$ perspective taking; $\mathrm{EC}=$ empathic concern (sympathy); $\mathrm{PD}=$ personal distress; $\mathrm{FE}=$ fantasy empathy. Correlations partialed sex, order of films, and social desirability.

${ }^{*} p<.10 .^{* *} p<.05 .^{* * *} p<.01 .{ }^{* * * *} p<.001$.

SC was not significantly related to participants' report of the degree to which emotions were expressed in the home of origin, although there were marginally significant relations indicating that dominant negative expressivity was associated with low levels of SC during the distress film (see Table 5). For HR, acceleration during the distressing film was associated with the expression of positive dominant emotion for women; however, given the small number of relations for HR, this (as well as the finding for SC) may be due to chance.

\section{Discussion}

The results of the present study support the claim that personal variables, including dispositional characteristics of the individual and one's socialization history, are related to the degree to which adults react vicariously to sympathy-evoking and distressing stimuli. However, the relations vary as a function of the type of stimulus and the type of assessment of vicarious responding.

Adults clearly responded differently to the distressing and sympathy-evoking films used in this study. They reported more sympathy in reaction to the sympathy-evoking film and exhibited HR deceleration (which has previously been associated with other-oriented attention) when viewing the most evocative portion of this tape. In contrast, adults reported more distress and exhibited more SC in reaction to the distressing film. This pattern indicates that the films were perceived as expected and supports the notion that distress is associated with more arousal than is compassion, sympathy, or empathic sadness (Shaver et al., 1987). Moreover, the facts that (a) self-reported sympathy during the sympathy film was associated with HR deceleration and (b) self-reported distress during the distress film was correlated with higher SC are consistent with the conclusion that our self-report indexes of state emotional responding were valid.

Table 5

Correlations of Family Expressivity With Vicarious Emotional Responding (Partialing Order and Social Desirability)

\begin{tabular}{|c|c|c|c|c|c|c|c|c|c|c|}
\hline \multirow{3}{*}{$\begin{array}{c}\text { Family } \\
\text { variable }\end{array}$} & \multicolumn{5}{|c|}{ Sympathy film } & \multicolumn{5}{|c|}{ Distress film } \\
\hline & \multicolumn{3}{|c|}{ Self-report } & \multirow[b]{2}{*}{ SC } & \multirow[b]{2}{*}{ HR } & \multicolumn{3}{|c|}{ Self-report } & \multirow[b]{2}{*}{ SC } & \multirow[b]{2}{*}{ HR } \\
\hline & Sympathy & Sad & Distress & & & Sympathy & Sad & Distress & & \\
\hline \multicolumn{11}{|l|}{ PE } \\
\hline All & $.20 *$ & $.27^{* *}$ & $.19 *$ & .12 & $-.19 *$ & .10 & $.32 * * *$ & .13 & .13 & .17 \\
\hline Women & $.35^{* *}$ & $.46^{* * * * *}$ & $.39^{* * *}$ & .15 & .11 & $.34^{* *}$ & $.54^{* * * *}$ & .24 & -.01 & $.39 *$ \\
\hline Men & .16 & -.03 & -.10 & -.02 & -.23 & -.15 & .08 & .02 & $.29 *$ & -.09 \\
\hline \multicolumn{11}{|c|}{ Dominant NE } \\
\hline All & -.09 & -.15 & $-.20^{*}$ & -.04 & -.12 & .14 & -.12 & .12 & $-.19^{*}$ & .02 \\
\hline Women & -.10 & -.18 & -.16 & -.10 & -.05 & .13 & -.14 & .12 & $-.29^{*}$ & -.07 \\
\hline Men & -.23 & -.11 & -.24 & -.12 & -.19 & .05 & -.11 & .00 & -.22 & .06 \\
\hline \multicolumn{11}{|c|}{ Submissive NE } \\
\hline All & $.26^{* *}$ & $.24^{* *}$ & .17 & .16 & -.07 & $.29 * * *$ & $.34 * * * *$ & $.37^{* * * *}$ & .16 & .09 \\
\hline Women & .23 & $.34^{* *}$ & $.43^{* * *}$ & .11 & .04 & $.31^{* *}$ & $.45^{* * *}$ & $.44^{* * * *}$ & .07 & .17 \\
\hline Men & .19 & .15 & -.03 & .11 & -.13 & .17 & .23 & .23 & .14 & -.07 \\
\hline
\end{tabular}

Note. $\mathrm{SC}=$ skin conductance; $\mathrm{HR}=$ heart rate; $\mathrm{PE}=$ positive expressivity; $\mathrm{NE}=$ negative expressivity.

${ }^{*} p<.10$. ${ }^{* *} p<.05$. ${ }^{* * *} p<.01 .{ }^{* * * *} p<.001$. 
As predicted, dispositional indexes of emotional intensity and vicarious arousability were associated with higher levels of vicarious responsivity to the films. With regard to self-reported reactions, high levels of dispositional affective intensity were associated with subjects' reported vicarious negative emotion (especially distress) in response to the distressing film. Dispositional affective intensity, which appears to be correlated with arousability for negative emotions (Derryberry \& Rothbart, 1988), was also associated with $\mathrm{SC}$ in reaction to the sympathy-evoking tape. In addition, dispositional fantasy empathy - the tendency to respond emotionally to fantasy media such as books, movies, and playswas positively related to the degree to which subjects exhibited $\mathrm{SC}$ in reaction to both films. Thus, our data are consistent with the conclusion that individual differences in emotional arousability are associated with higher levels of vicarious responding (Larsen et al., 1987). This finding is particularly noteworthy in that the pattern held for a nonverbal index of vicarious responding and when social desirability was partialed in the analyses.

The relations of personal distress and cognitive perspective taking to vicarious responding occurred only for self-report indexes of situational responding to the sympathy-evoking tape and primarily for subjects instructed to empathize (rather than watch objectively). In keeping with theoretical expectations and some prior research (e.g., Eisenberg, Miller, et al., 1989), dispositional perspective taking was positively related to reported vicarious reactions to the sympathy tape, whereas personal distress was negatively related to reported sympathy and tended to be positively related to reported distress in reaction to that tape. This negative relation of personal distress to reported sympathy was found only when sex and social desirability were partialed from the correlation; this may explain why the negative relation usually has not been found in the limited prior research. Given that the Davis (1983) dispositional scales refer to people's emotional reactions to others in need or emotional distress, it is not surprising that they related primarily to reactions to the sympathy-evoking tape and did not relate when subjects were explicitly told to suppress emotional reactions. In addition, the sympathy film, but not the distressing film, was presented as being about a real-life person (indeed, the sympathy film was a documentary about a real child); moreover, the distressing film was chosen because it was expected to elicit primarily fear and little consideration of the story protagonist's welfare. Consequently, reactions to the distressing film were relatively unlikely to be related to dispositional perspective taking or sympathy.

The patterns of findings for perspective taking and personal distress generally were as predicted in the imagine condition; however, there were no associations between dispositional sympathy and the indexes of vicarious emotional responding. This may be for at least two reasons. The protagonist in the sympathy film, a child with spina bifida, generally appeared to be in good spirits and was not depicted as being in real immediate need or distress (although one could sympathize with her chronic problems). Thus, the film may have elicited less sympathy than some films used in prior research. In support of this notion, report of sympathy in reaction to the sympathy film was relatively low $(M$ $=4.84$ ) as rated on a 7-point scale. In addition, the fact that we partialed social desirability, order, and sex (especially the latter) from the correlation between empathic concern and situational sympathy influenced the magnitude of the correlation (see Table $4)$; much of the variance in scores on EC and situational sympathy was gender related.

Consistent with the notion that supportive, sympathetic families rear empathic children (Barnett, 1987), family cohesion was positively related to self-reported sadness and sympathy; Staub (1986) has argued that empathy and sympathy are more likely if one is emotionally connected to others and that emotional connectedness may require a positive self-concept, a well-developed sense of other people, and the positive evaluation of human beings in general. Similarly, Kestenbaum, Farber, and Sroufe (1989) have argued (and have provided data to support their assertions) that the quality of the parent-child attachment affects children's interpersonal closeness and emotional sharing and that caring families provide other-oriented prototypic models of self, others, and relationships. Our data suggest that perceived family support and warmth not only influence children's tendencies to attend to others' emotional states but also have effects in adulthood. Additional work in which prospective data are obtained would be useful for verifying causal relations.

In addition, for women, reported vicarious responding to both films was associated with being raised in families in which positive emotions and submissive negative emotions (but not aggressive, nonreconciliatory negative dominant emotions) were perceived to be frequently expressed. Being reared in an expressive family may increase offsprings' awareness of their own emotional responses (Dunn et al., 1987) and their willingness to report emotional reactions (although it is impossible to draw causal conclusions from our data). It is unclear why the findings in this regard were primarily for women; perhaps, because expressivity is viewed as a feminine trait (Spence \& Helmreich, 1978), boys and men in expressive families are not particularly encouraged to be expressive. Alternatively, other societal influences that reinforce gender-stereotypic responding in regard to emotional reactions may undercut the influence of expressive families on male children's emotional expressivity (or their willingness and ability to acknowledge emotionality; Fuchs \& Thelen, 1988). In either case, our findings are consistent with Buck's (1984) finding that men learn to express emotion internally whereas women are more overtly expressive.

Dispositional indexes of perspective taking and personal distress as well as reported family functioning tended to be associated with self-report indexes of vicarious responding, whereas indexes tapping general emotional intensity and imaginal arousability were associated with SC and, for the former, with self-reported reactions to the distressing film. People who are aware of their own dispositional PT and PD and are willing to acknowledge them would be expected to be especially likely to report situational reactions, as would people raised in homes in which the overt expression of affect was acceptable (Halberstadt, 1986). The fact that these same people did not exhibit higher levels of physiological response is consistent with prior findings in which verbal reports of emotion and physiological response were unrelated or only weakly related (e.g., Craig \& Lowery, 1969; Eisenberg, Fabes, et al., 1989; Notarius \& Levenson, 1979) and with the very limited relations between SC and self-reported reactions in the present study; Physiological responding and overt expressive responding (e.g., facial reactions and verbal reactions) seem 
to be different channels of reactivity that are not highly related (and sometimes may even be negatively related; Buck, 1984). Therefore, it may be advantageous to use both self-reported and physiological indexes in studies of emotional responding.

It is particularly interesting that dispositional indexes of emotional intensity and fantasy empathy were associated with SC reactivity to the films. These data suggest that people who are emotionally arousable exhibit SC in situations involving vicarious emotion. Thus, dispositional characteristics seem to be related to channel of expression of vicariously induced emotional responses.

As in a previous study involving adults (Eisenberg, Schaller, et al., 1988), HR acceleration and deceleration in the present study did not appear to relate to dispositional indexes of vicarious responding, arousal, or family functioning. HR does not seem to be a very reliable index of arousal, presumably because of its involvement in the orienting response (Zillman, 1982). In contrast, HR was associated with situational reports of sympathy in reaction to the sympathy film. This pattern of findings might be due to $\mathrm{HR}$, as we have used it, being primarily an index of focus of attention and being highly situationally dependent. We assessed HR acceleration or deceleration during very specific, evocative portions of films; we were not using HR as a general measure of arousability or some related construct. Thus, it is not surprising that HR has seldom related to any of our dispositional measures, although HR sometimes is associated with both situational, self-reported reactions and prosocial behavior directed toward the object of one's vicarious emotion (e.g., Eisenberg, Fabes, et al., 1989).

Finally, note that women not only reported more vicarious emotional responding but also exhibited more emotional responding as indexed with SC. These findings support the view that there is a real difference in the vicarious responding of men and women and that women do not simply report more vicarious responding because of self-presentational or other-presentational concerns (Eisenberg \& Lennon, 1983). In other studies, women generally have not exhibited more SC responding in reaction to emotion-evoking stimuli or stressful situations; indeed, men frequently exhibit more (e.g., Buck, Savin, Miller, \& Caul, 1972; Craig \& Lowery; 1969). Our results may differ from some previous results because SC was standardized within individuals, a procedure that controls for individual differences (and any sex difference) in general SC responding. Although men may be internal in their response to emotional stimuli, women may be relatively more responsive when viewing particularly evocative portions of films involving others' welfare. Clearly, this is an issue meriting further study.

\section{References}

Archer, R. L. (1984). The farmer and the cowman should be friends: An attempt at reconciliation with Batson, Coke, and Pych. Journal of Personality and Social Psychology, 46, 709-711.

Barnett, M. A. (1987). Empathy and related responses in children. In N. Eisenberg \& J. Strayer (Eds.), Empathy and its development (pp. 46162). Cambridge, England: Cambridge University Press.

Batson, C. D. (1987). Prosocial motivation: Is it ever truly altruistic? In L. Berkowitz (Ed.), Advances in experimental social psychology (Vol. 20, pp. 65-122). San Diego, CA: Academic Press.

Batson, C. D., Bolen, M. H., Cross, J. A., \& Neuringer-Benefiel, H. E.
(1986). Where is the altruism in the altruistic personality? Journal of Personality and Social Psychology, 50, 212-220.

Batson, C. D., Dyck, J. L., Brandt, J. R., Batson, J. G., Powell, A. L., McMaster, M. R., \& Griffitt, C. (1988). Five studies testing two new egoistic alternatives to the empathy-altruism hypothesis. Journal of Personality and Social Psychology, 55, 52-77.

Ben-Shakhar, G. (1987). The correction of psychophysiological measures for individual differences in responsivity should be based on typical response parameters: A reply to Stemmler. Psychophysiology, 24, 247-249.

Buck, R. (1984). The communication of emotion. New York: Guilford Press.

Buck, R., Savin, V., Miller, R. E., \& Caul, W. F. (1972). Nonverbal communication of affect in humans. Journal of Personality and Social Psychology, 23, 362-371.

Cacioppo, J. T., \& Sandman, C. A. (1978). Physiological differentiation of sensory and cognitive tasks as a function of warning processing demands and reported unpleasantness. Biology Psychology, 6, 181192.

Campos, J. J., Butterfield, P., \& Klinnert, M. (1985, April). Cardiac and behavioral differentiation of negative emotional signals: An individual differences perspective. Paper presented at the biennial meeting of the Society for Research on Child Development, Toronto, Ontario, Canada.

Chlopan, B. E., McCain, M. L., Carbonell, J. L., \& Hagen, R. L. (1985). Empathy: Review of available measures. Journal of Personality and Social Psychology, 48, 635-653.

Cialdini, R. B., Schaller, M., Houlihan, D., Arps, K., Fultz, J., \& Beaman, A. (1987). Empathy-based helping: Is it selflessly or selfishly motivated? Journal of Personality and Social Psychology, 52, 749-758.

Coke, J. S. (1980). Empathic mediation of helping: Egoistic or altruistic? Dissertation Abstracts International, 41, 405B. (University Microfilms No. 80-14, 371)

Craig, K. D. (1968). Physiological arousal as a function of imagined, vicarious, and direct stress experiences. Journal of Abnormal Psychology, 73, 513-520.

Craig, K. D., \& Lowery, H. J. (1969). Heart-rate components of conditioned vicarious autonomic responses. Journal of Personality and Social Psychology, 11, 381-387.

Crowne, D. P., \& Marlowe, D. (1964). The approval motive. New York: Wiley.

Davis, M. H. (1983). Measuring individual differences in empathy: Evidence for a multidimensional approach. Journal of Personality and Social Psychology, 44, 113-126.

Davis, M. H., Hull, J. G., Young, R. D., \& Warren, G. G. (1987). Emotional reactions to dramatic film stimuli: The influence of cognitive and emotional empathy. Journal of Personality and Social Psychology, 52, 126-133.

Derryberry, D., \& Rothbart, M. K. (1988). Arousal, affect, and attention as components of temperament. Journal of Personality and Social Psychology, 55, 958-966.

Dunn, J., Bretherton, I., \& Munn, P. (1987). Conversations about feeling states between mothers and their young children. Developmental Psychology, 23, 132-139.

Edelberg, R. (1972). Electric activity of the skin: Its measurement and uses in psychophysiology. In N. S. Greenfield \& R. A. Sternbach (Eds.), Handbook of psychophysiology (pp. 367-418). New York: Holt, Rinehart \& Winston.

Eisenberg, N., Fabes, R. A., Bustamante, D., Mathy, R. M., Miller, P., \& Lindholm, E. (1988). Differentiation of vicariously induced emotional reactions in children. Developmental Psychology, 24, 237- 246. 
Eisenberg, N., Fabes, R. A., Miller, P. A., Fultz, J., Mathy, R. M., Shell, R., \& Reno, R. R. (1989). The relations of sympathy and personal distress to prosocial behavior: A multimethod study. Journal of Personality and Social Psychology, 57, 55-66.

Eisenberg, N., \& Lennon, R. (1983). Sex differences in empathy and related capacities. Psychological Bulletin. 94, 100-131.

Eisenberg, N., \& Miller, P. A. (1987). The relation of empathy to prosocial and related behavior. Psychological Bulletin, 101, 91-119.

Eisenberg, N., Miller, P. A., Schaller, M., Fabes, R. A., Fultz, J., Shell, R., \& Shea, C. (1989). The role of sympathy and altruistic personality traits in helping: A re-examination. Journal of Personality, 57, 41-67.

Eisenberg, N., Schaller, M., Fabes, R. A., Bustamante, D., Mathy, R., Shell, R., \& Rhodes, K. (1988). The differentiation of personal distress and sympathy in children and adults. Developmental Psychology, 24, 766-775.

Eisenberg, N., Shea, C. L., Carlo, G., \& Knight, G. (in press). Empathyrelated responding and cognition: A "chicken and the egg" dilemma. In W. Kurtines (Ed.), Advances in moral development. Hillsdale, NJ: Erlbaum.

Fabes, R. A., Eisenberg, N., \& Miller, P. (1990). Maternal correlates of children's vicarious emotional responsiveness. Developmental Psychology, 26, 639-648.

Feshbach, N. D. (1987). Parental empathy and child adjustment/maladjustment. In N. Eisenberg \& J. Strayer (Eds.), Empathy and its development (pp. 271-291). Cambridge, England: Cambridge University Press.

Fuchs, D., \& Thelen, M. H. (1988). Children's expected interpersonal consequences of communicating their affective state and reported likelihood of expression. Child Development, 59, 1314-1322.

Fultz, J. (1984). Guilt-avoidance versus altruistic motivation as mediators of the empathy-helping relationship. Dissertation Abstracts International, 46, 13808. (University Microfilms No. 8513744)

Fultz, J., Batson, C. D., Fortenbach, V. A., McCarthy, P. M., \& Varney, L. L. (1986). Social evaluation and the empathy-altruism hypothesis. Journal of Personality and Social Psychology, 50, 761-769.

Graham, F. K. (1978). Constraints on measuring heart rate and period sequentially through real and cardiac time. Psychophysiology, 15, 492495.

Halberstadt, A. G. (1986). Family socialization of emotional expression and nonverbal communication styles and skills. Journal of Personality and Social Psychology, 51, 827-836.

Hoffman, M. L. (1982). The measurement of empathy. In C. E. Izard (Ed.), Measuring emotions in infants and children (pp. 279-296). Cambridge, England: Cambridge University Press.

Jackson, J. C. (1974). Amplitude and habituation of the orienting reflex as a function of stimulus intensity. Psychophysiology, 11, 647-659.

Kestenbaum, R., Farber, E. A., \& Sroufe, L. A. (1989). Individual differences in empathy among preschoolers: Relation to attachment history. In N. Eisenberg (Ed.), New directions for child development: Vol. 44. Empathy and related emotional responses (pp. 51-64). San Francisco: Jossey-Bass.

Krebs, D. (1975). Empathy and altruism. Journal of Personality and Social Psychology, 32, 1134-1146.

Lacey, J. I., Kagan, J., Lacey, B. C., \& Moss, H. A. (1963). The visceral level: Situational determinants and behavioral correlates of autonomic response patterns. In P. H. Knapp (Ed.), Expression of the emotions in man (pp. 161-196). New York: International Universities Press.

Lanzetta, J. T., Cartwright-Smith, J., \& Kleck, R. E. (1976). Effects of nonverbal dissimulation on emotional experience and autonomic arousal. Journal of Personality and Social Psychology, 33, 354-370.
Larsen, R. J., Diener, E., \& Cropanzano, R. S. (1987). Cognitive operations associated with individual differences in affect intensity. Journal of Personality and Social Psychology, 53, 767-774.

Larsen, R. J., Diener, E., \& Emmons, R. A. (1986). Affect intensity and reactions to daily life events. Journal of Personality and Social Psychology, 51, 803-814.

Lazarus, R. S. (1974). A cognitively oriented psychologist looks at biofeedback. American Psychologist, 30, 553-561.

Malatesta, C. Z., \& Haviland, J. M. (1985). Signals, symbols, and socialization: The modification of emotional expression in human development. In M. Lewis \& C. Saarni (Eds.), The socialization of emotions (pp. 89-116). New York: Plenum Press.

Mehrabian, A. (1980). Basic dimensions for a general psychological theory. Cambridge, MA: Oelgeschlager, Gunn, \& Hain.

Moos, R. H., \& Moos, B. S. (1981). Family Environment Scale manual. Palo Alto, CA: Consulting Psychologists Press.

Notarius, C. I., \& Levenson, R. W. (1979). Expressive tendencies and physiological response to stress. Journal of Personality and Social Psychology, 7, 1204-1210.

Schroeder, D. A., Dovidio, J. E, Sibicky, M. E., Matthews, L. L., \& Allen, J. L. (1988). Empathic concern and helping behavior: Egoism or altruism? Journal of Experimental Social Psychology, 24, 333-353.

Schwartz, G. E. (1986). Emotion and psychophysiological organization: A systems approach. In M. G. H. Coles, E. Donchin, \& S. W Porges (Eds.), Psychophysiology: Systems, processes, and applications (pp. 354-377). New York: Guilford Press.

Shaver, P., Schwartz, J., Kirson, D., \& O’Connor, C. (1987). Emotion knowledge: Further exploration of a prototype approach. Journal of Personality and Social Psychology, 52, 1061-1086.

Spence, J. T., \& Helmreich, R. L. (1978). Masculinity and femininity: Their psychological dimensions, correlates, and antecedents. Austin: University of Texas Press.

Staub, E. (1978). Positive social behavior and morality: Social and personal influences (Vol. 1). San Diego, CA: Academic Press.

Staub, E. (1986). A conception of the determinants and development of altruism and aggression: Motives, the self, and the environment. In C. Zahn-Waxler, E. M. Cummings, \& R. Iannotti (Eds.), Altruism and aggression: Biological and social origins (pp. 135-164). Cambridge, England: Cambridge University Press.

Stemmler, G. (1987). Standardization within subjects: A critique of BenShakhar's conclusions. Psychophysiology, 24, 243-246.

Stotland, E., Mathews, K. E., Sherman, S. E., Hansson, R. O., \& Richardson, B. Z. (1978). Empathy, fantasy, and helping. Beverly Hills, CA: Sage.

Strayer, J., \& Schroeder, M. (1989). Children's helping strategies: Influences of emotion, empathy, and age. In N. Eisenberg (Ed.), New directions for child development: Vol. 44, Empathy and related emotional responses (pp. 85-105). San Francisco: Jossey-Bass.

Zahn-Waxler, C., Radke-Yarrow, M., \& King, R. A. (1979). Child rearing and children's prosocial initiations toward victims of distress. Child Development, 50, 319-330.

Zillman, D. (1982). Television viewing and arousal. In D. Pearl, L. Bouthilet, \& J. Lazar (Eds.), Television and social behavior. Vol. 2. Technical reports (pp. 53-67). Washington, DC: U.S. Government Printing Office.
Submitted December 1989;

Revised October 1990; Accepted November 1990. 